\title{
Associations between adolescents' sleep duration, sleep satisfaction, and suicidal ideation
}

\author{
Yoonjung Kim, ' Kyunghee Kim, ${ }^{1}$ Hye-Jin Kwon, ${ }^{1}$ Ji-su Kim'
}

Original article

\section{ABSTRACT}

\section{Introduction}

Both sleep and suicide are important issues among adolescents. Despite the extensive literature explaining short sleep duration as an important suicide risk factor, most previous studies did not consider sleep quality.

\section{Objective}

This study identified associations between sleep duration, sleep satisfaction, and suicidal ideation in adolescents.

\section{Method}

This cross-sectional study analyzed 58848 adolescents using raw data from the tenth Korea Youth Risk Behavior Web-based Survey conducted by Korea's Center for Disease Control and Prevention. Analyses incorporated sampling weights to account for the complex sampling design.

\section{Results}

In multivariate analysis, suicidal ideation of participants sleeping less than four hours was 1.36 times higher than that of participants sleeping more than nine hours. Sleep satisfaction was 1.20 times higher when moderate, 1.38 times higher when dissatisfied, and 1.64 times higher when very dissatisfied than when very satisfied.

\section{Discussion and conclusion}

It is necessary not only to improve sleep quality, but also to extend sleep duration in order to prevent adolescent suicide. If it is actually difficult to extend sleep duration due to school, a plan to increase subjective sleep satisfaction by improving sleep quality is required. This study showed the association between sleep duration and sleep satisfaction in adolescents. Therefore, in order to prevent adolescent suicide, it is necessary not only to extend their sleep duration, but also to improve their sleep quality.

Key words: Adolescent, sleep, personal satisfaction, suicidal ideation.

\section{RESUMEN}

\section{Antecedentes}

Tanto el sueño como el suicidio son temas importantes que afectan a los adolescentes. Pese a la abundante literatura que describe una corta duración del sueño como un importante factor de riesgo de suicidio, muchas investigaciones anteriores no han considerado la calidad del sueño.

\section{Objetivo}

Este estudio identificó algunas asociaciones entre la duración del sueño, la satisfacción del sueño y la ideación suicida en adolescentes.

\section{Método}

Este estudio transversal analizó los casos de 58848 adolescentes a partir de los datos brutos de la décima encuesta basada en la Página Web de Comportamiento Riesgoso de la Juventud Coreana realizada por el Centro Coreano para el Control y la Prevención de Enfermedades. Los análisis incluyeron pesos de muestreo para dar cuenta del complejo diseño de muestreo.

\section{Resultados}

En el análisis multivariado, la ideación suicida de los participantes que dormían menos de cuatro horas fue 1.36 veces mayor que la de los participantes que dormían durante más de nueve horas. La satisfacción del sueño era 1.20 veces mayor en los casos moderados, 1.38 veces mayor en los insatisfechos y 1.64 veces mayor en los casos muy insatisfechos que en los muy satisfechos.

\section{Discusión y conclusión}

Es necesario mejorar la calidad del sueño y alargar también su duración con el fin de prevenir el suicidio adolescente. Si es difícil extender la duración del sueño debido a los horarios escolares, se debe aplicar un plan para aumentar la satisfacción subjetiva del sueño mediante la mejora de la calidad del sueño. Este estudio demostró la asociación entre la duración y la satisfacción del sueño en los adolescentes. Por lo tanto, con el fin de prevenir el suicidio adolescente, es necesario alargar no sólo la duración del sueño, sino mejorar también su calidad.

Palabras clave: Adolescente, sueño, satisfacción personal, ideación suicida.

Red Cross College of Nursing, Chung-Ang University, Seoul, Republic of Korea.

Correspondence: Ji-su Kim. Red Cross College of Nursing. Chung-Ang University. 84 Heukseok-ro, Dongjak-gu, Seoul 156-756, Republic of Korea. Office: (82-2) 820 - 6856. Fax: (82-2) 824 - 7961. E-mail: jisu80@cau.ac.kr; jisu-1980@hanmail.net

Received first version: October 28, 2015. Second version: April 11, 2016. Accepted: May 24, 2016. 


\section{INTRODUCTION}

Sleep plays an important role in the brain's reparative and integrative processes. ${ }^{1}$ In particular, adolescence is the time when circadian rhythm changes; it is also time for adolescents to easily suffer from lack of sleep because bedtimes become later but school time is fixed. Thus, there is a high risk for sleep problems. ${ }^{2}$ Generally, a sleep duration of at least 8.5 hours per day is recommended for adolescents, ${ }^{3}$ but in reality the sleep duration of many adolescents falls short of this. Actually, only $62 \%$ of the European adolescents and $15.5 \%{ }^{4}$ of the Korean adolescents slept for more than eight hours on weekdays, ${ }^{5}$ indicating that short adolescent sleep duration is a serious concern in Korea. In fact, short sleep duration causes adverse consequences in individuals' physical and mental health. ${ }^{3,6,7}$ Therefore, sufficient sleep duration is important to prevent social and public health problems. ${ }^{8}$

In 2015, Korean adolescents (12-21 year old) accounted for $12.1 \%$ or 6139000 of the total population of $50617000 .{ }^{9}$ According to the Organization for Economic Cooperation and Development (OECD), the suicide rate per $100000 \mathrm{Ko}-$ reans is 29.1, which is the highest among OECD countries. ${ }^{10}$ Korea's suicide rate for 2013 was 1.3 per 100000 individuals for ages 10-14, 7.9 for ages 15-19, and 14.5 for ages 20-24, showing that suicide deaths increase as adolescence progresses. ${ }^{11}$ Additionally, Korea's suicide rate is increasing among adults as well. Prevention education and intervention for adolescent suicide are urgent because youngsters in the suicide high-risk group are highly likely to proceed to the high-risk group even in adulthood. ${ }^{12}$ Therefore, both suicide and short sleep duration are key health issues for Korean adolescents.

According to previous research, youth suicidal ideation is caused by multi-dimensional components such as psychological factors including depression, stress, and low self-esteem; ${ }^{13,14}$ family factors including family support; ${ }^{15,16}$ and external factors including school life, friends, relationships, etc. ${ }^{15-17}$ Moreover, several studies have investigated the possible association between sleep and suicide. Short sleep duration has now been identified as a potential suicidality risk factor among adolescents. ${ }^{1,5,18,19}$ Despite the extensive literature exposing short sleep duration as an important suicide risk factor, most previous studies did not consider sleep quality. However, subjective sleep satisfaction should be also considered because individual sleep duration is relatively rather than absolutely determined. ${ }^{20}$ Moreover, most sleep-related studies are limited by small sample sizes and do not represent the general population. ${ }^{8}$ Therefore, this study identified the association between adolescents' sleep satisfaction and suicidal ideation as well as self-reported sleep duration using a nationally representative sample to ultimately prevent problems due to adolescents' short sleep duration and suicide. The specific purposes of this study are as follows: 1. To evaluate the differences in suicidal ideation by demographic characteristics of adolescents; 2 . To examine the relationship of suicidal ideation with sleep satisfaction depending on the sleeping time of adolescents; and 3. To investigate the association between sleep duration, sleep satisfaction, and suicidal ideation of adolescents.

\section{METHOD \\ Study design and study sample}

This cross-sectional study identified the association of sleep duration, sleep satisfaction, and suicidal ideation in Korean adolescents. We used the raw data of the tenth Korea Youth Risk Behavior Web-based Survey (KYRBWS-X) conducted by Korea's Center for Disease Control and Prevention (KCDC).

KYRBWS is an anonymous self-administered online survey targeting middle school freshmen to high school seniors to identify health behaviors of Korean adolescents. It was conducted using a complex sample design involving stratification, clustering, and multistage sampling methods. In order to minimize sampling errors in the population stratification stage, the researcher divided the population into 129 levels using the area group and schools (middle schools, academic high schools, and specialized professional high schools) as a stratification variable and then allocated the number of sample schools by applying the proportional allocation method to ensure that the sample composition ratio and the composition ratio of population by stratification variable is consistent. Finally, sampling was done by the stratification colony extraction method with school as the first extraction unit and class as the second extraction unit. ${ }^{21}$ More details about sampling strategies and analysis guidelines for raw data are shown on the center's homepage (http://yhs.cdc.go.kr). ${ }^{21}$

KYRBWS-X surveyed 74167 individuals from 400 middle and 400 high schools; 72060 people participated in the survey, showing a participation rate of $97.2 \% .^{22}$ Of these, data from 13212 adolescents were processed as missing because the measured values of the variables for age (aged 12 or younger or 19 or older), wake up time (before 4:00 a.m., after 9:00 a.m.), sleeping time (4:00 a.m. - 8:00 p.m.) were

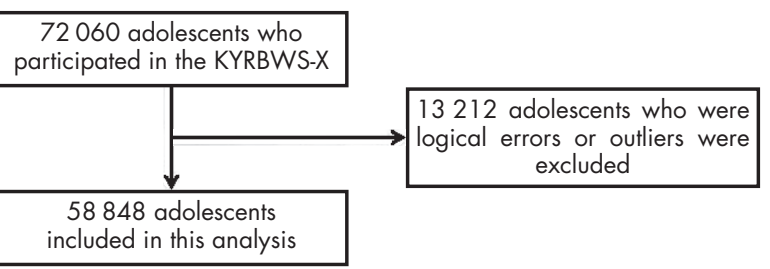

Figure 1. The flowchart of recruitment process. 
Table 1. Suicidal ideation according to demographic characteristics $(N=58848)$

\begin{tabular}{|c|c|c|c|c|c|c|c|c|}
\hline \multirow[b]{3}{*}{ Variable } & \multirow[b]{3}{*}{ Classification } & & & \multicolumn{4}{|c|}{ Suicidal ideation } & \multirow[b]{3}{*}{$\operatorname{tor} \chi^{2}(p)$} \\
\hline & & \multirow{2}{*}{\multicolumn{2}{|c|}{$\begin{array}{c}n(\%) \text { or } \\
\text { Mean } \pm \text { SE }\end{array}$}} & \multicolumn{2}{|c|}{ No } & \multicolumn{2}{|c|}{ Yes } & \\
\hline & & & & $\begin{array}{l}\%(S \\
\text { Mean }\end{array}$ & $\begin{array}{l}\text { E) or } \\
\pm S E\end{array}$ & $\begin{array}{l}\% \text { (SE } \\
\text { Mean }\end{array}$ & $\begin{array}{l}\text { E) or } \\
\pm S E\end{array}$ & \\
\hline Age & (years) & $15.03 \pm$ & $=0.02$ & 15.02 & \pm 0.02 & $15.22=$ & \pm 0.02 & 0.775 (.439) \\
\hline Body mass index & $\left(\mathrm{kg} / \mathrm{m}^{2}\right)$ & $20.73 \pm$ & $=0.01$ & 20.72 & \pm 0.04 & $20.83=$ & \pm 0.04 & $2.626(.009)$ \\
\hline Sleep duration & (hr) & $6.33 \pm$ & $=0.01$ & 6.38 & \pm 0.02 & $6.01=$ & \pm 0.02 & $19.737(<.001)$ \\
\hline \multirow[t]{2}{*}{ Gender } & Male & 29143 & $(51.1)$ & 52.4 & (1.3) & 41.8 & $(1.4)$ & $287.155(<.001)$ \\
\hline & Female & 29705 & $(48.9)$ & 47.6 & (1.3) & 58.2 & $(1.4)$ & \\
\hline \multirow[t]{2}{*}{ School type } & Middle school & 28876 & (47.4) & 47.1 & $(0.7)$ & 49.1 & $(1.0)$ & $9.940(.008)$ \\
\hline & High school & 29972 & $(52.6)$ & 52.9 & $(0.7)$ & 50.9 & $(1.0)$ & \\
\hline \multirow[t]{3}{*}{ Urban scale } & Big cities & 26452 & (44.0) & 43.9 & $(0.7)$ & 45.1 & $(0.9)$ & $4.544(.204)$ \\
\hline & Medium sized cities & 27846 & $(49.8)$ & 50.0 & $(0.8)$ & 48.7 & $(1.1)$ & \\
\hline & Country area & 4552 & $(6.2)$ & 6.2 & $(0.5)$ & 6.3 & $(0.6)$ & \\
\hline \multirow[t]{3}{*}{ Living with parents } & Both & 51927 & (88.6) & 89.0 & $(0.2)$ & 85.3 & $(0.4)$ & $90.258(<.001)$ \\
\hline & Only father or mother & 6113 & (10.2) & 9.8 & $(0.2)$ & 13.0 & $(0.4)$ & \\
\hline & None & 808 & (1.3) & 1.2 & $(0.1)$ & 1.7 & $(0.2)$ & \\
\hline \multirow{4}{*}{$\begin{array}{l}\text { Father's educational } \\
\text { background }\end{array}$} & Below middle school & 1691 & $(2.7)$ & 2.6 & $(0.1)$ & 3.4 & $(0.2)$ & $27.656(<.001)$ \\
\hline & High school & 18138 & (30.3) & 30.3 & $(0.4)$ & 30.4 & $(0.7)$ & \\
\hline & Above college & 29502 & (51.4) & 51.3 & $(0.5)$ & 52.2 & $(0.8)$ & \\
\hline & Unknown & 9517 & (15.5) & 15.7 & $(0.3)$ & 14.0 & $(0.5)$ & \\
\hline Mother's educational & Below middle school & 1471 & $(2.4)^{\prime}$ & 2.2 & $(0.1)$ & 3.2 & $(0.2)$ & $39.571(<.001)$ \\
\hline \multirow{3}{*}{ background } & High school & 23323 & $(39.5)$ & 39.5 & $(0.4)$ & 40.0 & $(0.7)$ & \\
\hline & Above college & 24835 & (43.0) & 43.0 & $(0.5)$ & 43.3 & $(0.8)$ & \\
\hline & Unknown & 9219 & (15.1) & 15.3 & $(0.3)$ & 13.5 & $(0.5)$ & \\
\hline \multirow[t]{5}{*}{ Perceived economic status } & Very high & 4495 & $(7.7)$ & 7.8 & $(0.2)$ & 7.1 & $(0.3)$ & $474.497(<.001)$ \\
\hline & High & 15683 & $(26.9)$ & 27.2 & $(0.3)$ & 24.6 & $(0.6)$ & \\
\hline & Moderate & 29021 & (49.0) & 49.8 & $(0.3)$ & 43.7 & $(0.6)$ & \\
\hline & Low & 7948 & (13.4) & 12.7 & $(0.2)$ & 18.9 & $(0.5)$ & \\
\hline & Very low & 1701 & $(2.9)$ & 2.5 & $(0.1)$ & 5.7 & $(0.3)$ & \\
\hline \multirow[t]{5}{*}{ Perceived school performance } & Very high & 7401 & (12.4) & 12.7 & $(0.2)$ & 10.8 & $(0.4)$ & $293.313(<.001)$ \\
\hline & High & 15143 & $(25.7)$ & 26.1 & $(0.2)$ & 22.8 & $(0.5)$ & \\
\hline & Moderate & 16790 & $(28.6)$ & 29.0 & $(0.2)$ & 25.8 & $(0.5)$ & \\
\hline & Low & 13812 & $(23.6)$ & 23.2 & $(0.2)$ & 26.1 & $(0.5)$ & \\
\hline & Very low & 5702 & (9.7) & 9.0 & $(0.1)$ & 14.5 & $(0.4)$ & \\
\hline \multirow[t]{3}{*}{ Subjective health status } & Good & 41961 & (71.3) & 73.7 & $(0.2)$ & 54.8 & $(0.6)$ & $1459.033(<.001)$ \\
\hline & Moderate & 13297 & $(22.6)$ & 11.3 & $(0.2)$ & 31.3 & $(0.5)$ & \\
\hline & Poor & 3591 & (6.1) & 5.0 & $(0.1)$ & 13.9 & $(0.4)$ & \\
\hline \multirow[t]{5}{*}{ Sleep satisfaction } & Very satisfied & 4262 & $(7.1)$ & 7.6 & $(0.1)$ & 3.8 & $(0.2)$ & $1506.778(<.001)$ \\
\hline & Satisfied & 11013 & (18.7) & 19.8 & $(0.2)$ & 11.2 & $(0.4)$ & \\
\hline & Moderate & 18905 & (32.2) & 33.1 & $(0.2)$ & 25.9 & $(0.5)$ & \\
\hline & Unsatisfied & 16779 & $(28.5)$ & 27.8 & $(0.3)$ & 33.4 & $(0.6)$ & \\
\hline & Very unsatisfied & 7889 & (13.5) & 11.7 & $(0.2)$ & 25.8 & $(0.5)$ & \\
\hline \multirow[t]{2}{*}{ Stress awareness } & Yes & 21699 & (36.8) & 31.3 & (0.3) & 74.5 & $(0.5)$ & $5186.298(<.001)$ \\
\hline & No & 37149 & (63.2) & 68.7 & $(0.3)$ & 25.5 & $(0.5)$ & \\
\hline Depression awareness & Yes & 43625 & (74.1) & 19.1 & $(0.2)$ & 26.7 & $(0.5)$ & $9902.154(<.001)$ \\
\hline & No & 15223 & $(25.9)$ & 80.9 & $(0.2)$ & 73.3 & $(0.5)$ & \\
\hline Lifetime drinking experience & Yes & 24665 & $(42.4)$ & 41.0 & $(0.4)$ & 52.6 & $(0.6)$ & $355.248(<.001)$ \\
\hline & No & 34183 & $(57.6)$ & 59.0 & $(0.4)$ & 47.7 & $(0.6)$ & \\
\hline Lifetime smoking experience & Yes & 10734 & (18.7) & 17.7 & $(0.4)$ & 26.3 & $(0.6)$ & $314.124(<.001)$ \\
\hline & No & 48114 & (81.3) & 82.3 & $(0.4)$ & 73.7 & $(0.6)$ & \\
\hline Experience of sexual intercourse & Yes & 2522 & $(4.6)$ & 4.1 & $(0.1)$ & 7.9 & $(0.3)$ & $220.529(<.001)$ \\
\hline & No & 56326 & (95.4) & 95.9 & $(0.1)$ & 92.1 & $(0.3)$ & \\
\hline Lifetime drug experience & Yes & 376 & $(0.6)$ & 0.5 & $(0.0)$ & 1.6 & $(0.1)$ & $133.328(<.001)$ \\
\hline & No & 58472 & (99.4) & 99.5 & $(0.0)$ & 98.4 & $(0.1)$ & \\
\hline
\end{tabular}

$\mathrm{SE}=$ Standard error 
logical errors or outliers (see parenthetical ranges) and were thus excluded from study analysis. Therefore, the responses of 58848 adolescents were analyzed in this study (figure 1).

\section{Study variables}

\section{Sleep duration and sleep satisfaction}

In this study, sleep duration was calculated by using the responses to "For the last seven days, what time do you usually go to bed and wake up on weekdays?" Sleep satisfaction used a five-point scale (1 point: not sufficient at all, 5 points: quite sufficient) to "For the last 7 days, do you think your sleep duration was enough to recover from fatigue?"

\section{Suicidal ideation}

In this study, we used responses to "For the last 12 months, have you ever seriously thought about suicide? (yes/no)" for suicidal ideation.

\section{Demographic characteristics}

In this study, the following demographic characteristics were used: age, gender, body mass index (BMI), school type (middle and high school), urban scale (big and medium sized cities and country areas), living with parents (both parents, only parent, and none), parents' educational backgrounds (below middle school, high school, above college and unknown), perceived economic status (very high, high, moderate, low, and very low), perceived school performance (very high, high, moderate, low, and very low), subjective health status (good, moderate, and poor), stress awareness (yes/no), depression awareness (yes/no), and experiences of lifetime drinking (yes/no), lifetime smoking (yes/no), lifetime drug use (yes/no), and lifetime sexual intercourse (yes/no).

\section{Statistical analysis}

Statistical analysis was performed using the SPSS Complex Sample, version 19.0 (SPSS Inc., Chicago, IL, USA) reflecting sampling weights and using nationally representative estimates according to KCDC guidelines. That is, all of the data were analyzed using a weighted value, stratification variable, and colony variable, which are complex sample design elements; of these, weighted value used a value presented by KCDC by using the extraction rate, response rate, and post correction rate (the sum of weighted values by grade, school, and gender in the area group is calculated to be equal to the national number of middle and high school students as of 2014).

Continuous variables (general participant characteristics) are presented as mean (SE) values, while categorical variables are presented as percentage (SE) values. The t-test and $\chi^{2}$ tests were used to compare suicidal ideation by demographic characteristics. Logistic regression analyses were performed to determine associations between sleep duration, sleep satisfaction, and suicidal ideation. Odds ratios (ORs) and confidence intervals (CIs) were estimated after adjusting for BMI, gender, school type, living with parents, parents' educational backgrounds, perceived economic status, subjective health status, stress awareness, depression awareness, lifetime drinking experience, lifetime smoking experience, experience of sexual intercourse, and lifetime drug experience. A cut-off value of $p<.05$ was used to select the adjusted variables in table 1 . A $p$-value of $<.05$ was considered statistically significant.

\section{RESULTS}

Differences in suicidal ideation according to adolescents' demographic characteristics are shown in table 1 . The rate of suicidal ideation was statistically significantly higher with: lower BMI; short sleep duration; females; the participant did not live with both parents; low parents' educational backgrounds; lower perceived economic status; lower subjective health status; unsatisfactory sleep; perceived stress or depression; experience of lifetime drinking, smoking, or drug use experience; and experience with sexual intercourse. The relationship between actual participant sleep duration and perceived sleep satisfaction is shown in figure 2. As sleep satisfaction improved, actual sleep duration also increased and there was a statistically significant difference. The associations between adolescents' sleep duration, sleep satisfaction, and suicidal ideation are shown in table 2. In univariate analysis, participant suicidal ideation was 1.35 times higher if sleeping for 5-6 hours and 2.12 times higher if sleeping for less than four hours than participants sleeping for more than nine hours. Sleep satisfaction was 1.58 times higher when moderate, 2.43 times higher when unsatisfied, and 4.44 times higher when very unsatisfied than when very satisfied. In multivariate analysis, participant suicidal

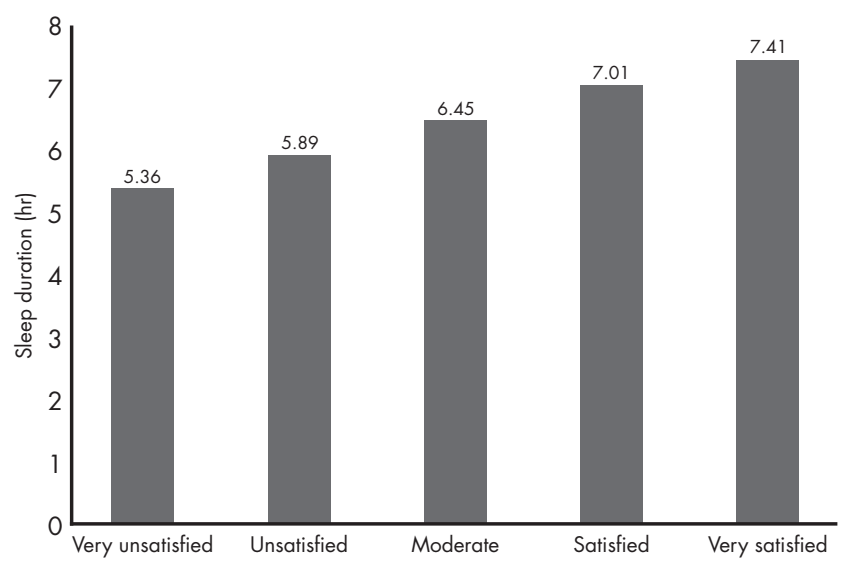

Figure 2. Association between sleep duration and sleep satisfaction among adolescents. 
Table 2. Association between sleep duration, sleep satisfaction and suicidal ideation among adolescents $(N=58848)$

\begin{tabular}{llcc}
\hline & & \multicolumn{2}{c}{ Suicidal ideation } \\
\cline { 3 - 4 } Variables & Classification & Oodel 1 & Model 2 \\
\hline Sleep duration & $\geq 9$ hours & 1 & OR [95\% Cl] \\
\hline & $7-8$ hours & $1.013[0.867-1.184]$ & $0.973[0.817-1.158]$ \\
& $5-6$ hours & $1.345[1.153-1.569]$ & $1.111[0.932-1.325]$ \\
Sleep satisfaction & $\leq 4$ hours & $2.122[1.802-2.500]$ & $1.367[1.130-1.652]$ \\
& Very satisfied & 1 & 1 \\
& Satisfied & $1.147[0.992-1.326]$ & $1.091[0.932-1.278]$ \\
& Moderate & $1.580[1.385-1.803]$ & $1.204[1.038-1.396]$ \\
& Unsatisfied & $2.432[2.126-2.781]$ & $1.385[1.192-1.609]$ \\
& Very unsatisfied & $4.442[3.872-5.097]$ & $1.645[1.410-1.919]$ \\
\hline
\end{tabular}

Model 1: univariate; Model 2: adjusted for BMl, gender, school type, living with parents, father's or mother's educational background, perceived economic status, subjective health status, stress awareness, depression awareness, lifetime drinking experience, lifetime smoking experience, experience of sexual intercourse and lifetime drug experience.

Note: $\mathrm{OR}=$ Odds ratio; $\mathrm{Cl}=$ Confidence interval.

ideation was 1.36 times higher if sleeping for less than four hours than participants sleeping for more than nine hours. Sleep satisfaction was 1.20 times higher when moderate, 1.38 times higher when unsatisfied, and 1.64 times higher when very unsatisfied than when very satisfied.

\section{DISCUSSION AND CONCLUSION}

As Korean adolescent suicide emerges as a major cause of juvenile deaths, social interest in its prevention is increasing.

Previous studies have also reported that being female, poor academic grades, low economic status, living with their parents, parents' poor educational background, subjective health status, drinking, smoking, stress, and depression affect suicidal ideation of adolescents; the results were similar to those of this study. ${ }^{14,15,23-26}$ It was also reported that drug experiences and sexual activity affect suicide attempts. ${ }^{26}$ Therefore, active interest and measures are needed to prevent suicidal ideation in female adolescents with low academic grades or difficult socio-economic status. Preventive education and programs for health risk behaviors are also required to prevent suicide. In multivariate logistic analysis, participant suicidal ideation for those sleeping for less than four hours was 1.36 times higher than participants sleeping for more than nine hours even after correcting for suicidal ideation impact factors. This is similar to the results of several previous studies ${ }^{1,5,18,19,28}$ completed across various cultural backgrounds that short sleep duration is a suicide impact factor. According to this study's results, the risk of suicidal ideation increased when sleep duration was less than four hours; previous studies ${ }^{5}$ in Korea also reported that the suicidal ideation risk of adolescents sleeping for less than five hours is high. However, studies in the U.S. ${ }^{2}$ found that the risk of suicidal ideation of adolescents sleeping for less than six hours was high. Particularly in Korean adolescents, the suicidal ideation risk increased statistically significantly in relatively shorter sleep durations compared to American ${ }^{2}$ or European adolescents. ${ }^{4}$ We propose the need for a cross-cultural study to determine if this result is a racial difference or related to the social environment. In the results of this study, suicidal ideation was 1.20 times higher when sleep satisfaction was moderate, 1.38 times higher when unsatisfied, and 1.64 times higher when very unsatisfied than when very satisfied. This is similar to the results of previous research ${ }^{23}$ showing lower suicidal ideation when sleep satisfaction is moderate or high and that insufficient sleep is related to suicidal ideation. ${ }^{1,29}$ Given that adolescents' lack of sleep increases the occurrence of emotional instability, depression, stress, etc., ${ }^{30,31}$ increased risk of suicide due to short sleep duration or unsatisfactory sleep may be a natural result. On the other hand, negative thoughts such as stress, depression, or anxiety make sleep difficult and also cause disruption in sleep duration. ${ }^{32-34}$ However, what is interesting in this study is that the suicidal ideation risk also increases when sleep satisfaction perceived by adolescents is moderate even after adjusting for suicidal ideation impact factors. This suggests clearly and strongly how important it is to achieve a satisfying sleep as well as to extend sleep duration in order to prevent adolescents' suicidal ideation. Sleep disturbances may damage individuals' emotional regulation, impulse control, and problem solving ability, which in turn increases the risk of adolescent suicidality. ${ }^{35-38}$

The relationship between actual sleep duration reported by adolescents and perceived sleep satisfaction was assessed. Higher satisfaction in adolescents' sleep increased actual sleep duration and this showed a statistically significant difference. Recommended sleep duration for adoles- 
cents is 8.5 hours per day. ${ }^{3}$ According to the results of this study, adolescents perceived that a sleep duration of about seven hours was indicated a satisfactory sleep. When considering this from a comprehensive perspective, it is necessary not only to improve sleep quality, but also to extend sleep duration in order to prevent adolescent suicide. Additionally, the underlying neurobiological factors can partially explain the relationship between sleep and suicide. That is, serotonergic neurotransmission was found to play a significant role in both sleeping and suicide. ${ }^{39,40}$ In reality, if it is difficult to extend sleep duration due to school, a plan to increase subjective sleep satisfaction by improving sleep quality is required. This study is significant in having identified the association between sleep satisfaction and suicidal ideation as well as sleep duration of adolescents. It also targeted a large and representative sample and corrected for all variables known to affect suicidal ideation.

Despite these strengths, the limitations of this study are as follows. This study considered only weekday sleep duration and did not include weekend sleep duration. Therefore, we suggest a study considering sleep duration of both weekdays and weekends. We also suggest the need for a further longitudinal study because this study is a cross-sectional study and cannot explain any causal relationship between sleep duration, sleep satisfaction, and suicidal ideation. Therefore, the time or quality of sleep may be degraded due to suicidal ideation. Finally, this study analyzed only the associations between sleep duration, sleep satisfaction, and suicidal ideation. Therefore, it is suggested that largescale research considering additional factors involved in adolescent suicidal ideation is needed.

This study showed that suicidal ideation risk is high when sleep duration is less than four hours and sleep satisfaction is less than moderate. Therefore, lack of sleep in addition to rapid physical changes and mental confusion are likely to increase suicidal ideation risk. This may lead to suicide attempts and suicides. In order to break this vicious cycle, teachers and parents need to instruct adolescents to sleep for more than five hours a day or improve subjective sleep satisfaction by improving sleep quality.

\section{Ethical considerations}

The KYRBWS is a statistical survey approved by the government (Approval No. 11758) that underwent KCDC institutional review board review (2014-06EXP-02-P-A). We requested permission from the KCDC to use the KYRBWS survey results for research purposes; we also submitted a data use plan and posted a written pledge on the KYRBWS homepage.

Ethical issues, including plagiarism, informed consent, misconduct, data fabrication and/or falsification, double publication and/or submission, redundancy, have been completely monitored by the author.

\section{Funding}

This study was not funded.

\section{Conflict of interests}

The authors have no conflict of interest to declare.

\section{REFERENCES}

1. Lee YJ, Cho SJ, Cho IH, Kim SJ. Insufficient sleep and suicidality in adolescents. Sleep 2012;35(4):455-460.

2. Fitzgerald CT, Messias E, Buysse DJ. Teen sleep and suicidality: results from the youth risk behavior surveys of 2007 and 2009. J Clin Sleep Med 2011;7(4):351-356.

3. Carskadon M, Acebo C, Seifer R. Extended nights, sleep loss, and recovery sleep in adolescents. Arch Ital Biol 2001;139(3):301-312.

4. Park H. Effect of sleep duration on suicidal ideation in Korean adolescents. J Korean Soc Sch Health 2015;28(1):1-9.

5. Garaulet M, Ortega F, Ruiz J et al. Short sleep duration is associated with increased obesity markers in European adolescents: effect of physical activity and dietary habits. The HELENA study. Int J Obes 2011;35(10):1308-1317.

6. Carskadon MA. Sleep deprivation: health consequences and societal impact. Med Clin North Am 2004;88(3):767-776.

7. Zee PC, Turek FW. Sleep and health: everywhere and in both directions. Arch Intern Med 2006;166(16):1686-1688.

8. Seo Di, So WY. Sleep duration and school performance in Korean adolescents. Salud Ment 2014;37(5):407-413.

9. Statistics Korea. 2015 Youth Statistics. 2015. http://www.kostat.go.kr/ portal/korea/kor_nw/2/1/index.board?bmode=read\&aSeq=335384

10. Organization for Economic Cooperation and Development (OECD). Suicide rates (indicator)2015. http://data.oecd.org/healthstat/suicide-rates.htm.

11. Korean Statistical Information Service. National statistics: causes of death 2015 (fecha última consulta 15-06-16). http://kosis.kr

12. Thompson M, Kuruwita C, Foster EM. Transition in suicide risk in nationally representative sample of adolescents. J Adolesc Health 2009;44:458-463.

13. Bell AB. An ecological risk factor examination of depression and suicide ideation in African American teenagers. Unpublished Doctoral Dissertation.Wisconsin: University of Wisconsin-Madison; 2007.

14. Sohn J. A structural model of impulsive suicidal ideation in adolescents. J Korean Acad Psychiatr Ment Health Nurs 2009;18(4):418-430.

15. Park J, Moon J. Factors affecting suicidal ideation of the middle and high school students in Korea. Health Soc Sci 2010;27:105-131.

16. Jang SH, Lee MA. A study on factors related to adolescents' suicide ideation: focusing on social support and buffering effects of selfesteem. Korean J Youth Studies 2010;17(8):27-55.

17. Medoff LR. Suicidal ideation and related factors in Native American adolescents with and without learning disabilities. Unpublished Doctoral Dissertation. Stanford: Stanford University; 2006.

18. Liu X. Sleep and adolescent suicidal behavior. Sleep 2004;27:1351-1358.

19. Yen CF, King BH, Tang TC. The association between short and long nocturnal sleep durations and risky behaviours and the moderating factors in Taiwanese adolescents. Psychiatry Res 2010;179(1):69-74.

21. Anderson C, Horne JA. Do we really want more sleep? A population-based study evaluating the strength of desire for more sleep. Sleep Med 2008;9(2):184-187.

22. Ministry of Education, Ministry of Health and Welfare, Korea Center for Disease Control and Prevention. The tenth Korea youth risk behavior web-based survey. Korea: 2015.

23. Sohn SY. Factors affecting suicidal iedation, suicidal plan and suicidal attempt in Korean adolescents. J Korea Academia-Industrial Cooperation Society 2014;15(3):1606-1614.

24. Jang S, Lee M. A study on factors related to adolescents' suicide ideation: Focusing on social support and buffering effects of self-esteem. Korean J Youth Stud 2010;17(8):27-55. 
25. Woo C, Park A, Jeong H. The structural relationship among human relations, stress, depression and suicidal ideation of adolescents by genders and level of school. Korean J Educ Psychol 2010;24:19-38.

26. Park J, Chung I. The effects of high school students' academic problems on suicidal ideation-focusing on the mediational effects of individual level risk and protective factors. J Korean Soc Child Welf 2010;32:69-97.

27. Park E. The influencing factors on suicide attempt among adolescents in South Korea. J Korean Acad Nurs 2008;38(3):465-473.

28. Rhie SK, Chae KY. Impact of sleep duration on emotional status in adolescents. J Depress Anxiety 2013;2(3):138.

29. An H, Ahn JH, Bhang SY. The association of psychosocial and familial factors with adolescent suicidal ideation: A population-based study. Psychiatry Res 2010;177(3):318-322.

30. Perlman CA, Johnson SL, Mellman TA. The prospective impact of sleep duration on depression and mania. Bipolar Disord 2006;8(3):271274.

31. Hale L. Bedtimes and the blues: evidence in support of improving adolescent sleep. Sleep 2010;33(1):17.

32. Ellis J, Cropley M. An examination of thought control strategies employedbyacuteandchronicinsomniacs. Sleep Medicine 2002;3(5):393400 .
33. Johnson EO, Roth T, Breslau N. Theassociation ofinsomnia with anxietydisordersanddepression:Explorationofthedirectionofrisk. J Psychiatric Research 2006;40:700-708.

34. Wicklow A, Espie CA. Intrusive thoughts and theirrelationship to actigraphic measurement of sleep: towards a cognitive model of insomnia. Behaviour Research Therapy 2000;38:670-693.

35. Abe T, Hagihara A, Nobutomo K. Sleep patterns and impulse control among Japanese junior high school students. J Adolesc 2010;33(5):633641.

36. Li D, Bao Z, Li X, Wang Y. Perceived school climate and Chinese adolescents' suicidal ideation and suicide attempts: the mediating role of sleep quality. J Sch Health 2016;86:75-83.

37. Wagner U, Gais S, Haider H, Verleger R et al. Sleep inspires insight. Nature 2004;427(6972):352-355.

38. Walker MP, van Der Helm E. Overnight therapy? The role of sleep in emotional brain processing. Psychol Bull 2009;135(5):731-748.

39. Bernert RA, Joiner TE. Sleep disturbances and suicide risk: A review of the literature. Neuropsychiatr Dis Treat 2007;3(6):735-743.

40. Ursin R. Serotonin and sleep. Sleep Med Rev 2002;6:57-69. 